\title{
Influence of Perilla frutescens var. acuta Water Extract on the Shelf Life and Physicochemical Qualities of Cooked Beef Patties
}

\author{
Cheol Woo Lee, Hyun Min Choi, Su Yeon Kim, Ju Ri Lee, Hyun Joo Kim¹, Cheorun Jo ${ }^{1}$, and Samooel Jung* \\ Department of Animal Science and Biotechnology, Chungnam National University, Daejeon 305-764, Korea \\ ${ }^{1}$ Department of Agricultural Biotechnology, Center for Food and Bioconvergence, and \\ Research Institute for Agriculture and Life Science, Seoul National University, Seoul 151-921, Korea
}

\begin{abstract}
This study investigated the effects of Perilla frutescens var. acuta water extract (WEP) on the shelf life and physicochemical qualities of cooked beef patties. The WEP contained phenolic compounds ( $80.65 \mathrm{mg}$ gallic acid equivalents/g) and had half-maximal effective concentrations of 0.437 and $4.509 \mathrm{mg} / \mathrm{mL}$ for scavenging of DPPH and ABTS ${ }^{+}$radicals, respectively. Treatment with $0.6 \%$ WEP inhibited the growth of Escherichia coli O157:H7 $(p<0.05)$. Based on the result of the antioxidative potential and antimicrobial potential of WEP, beef patties were prepared with three treatment groups: (1) beef patties without added antioxidant (control); (2) beef patties with $0.02 \%$ L-ascorbic acid (BAA); and (3) beef patties with 0.6\% WEP (BWEP). The pH and cooking loss of BWEP were lower and higher than those in the control, respectively $(p<0.05)$. When cooked beef patties were stored for $21 \mathrm{~d}$ at $4^{\circ} \mathrm{C}$, the total number of aerobic bacteria in BWEP was lower than those in the control on all days except day $14(p<0.05)$. The TBARS values in BWEP were lower than those of controls on days 7, 14, and $21(p<0.05)$. Compared to control and BAA, BWEP had lower $L^{*}$ and $b^{*}$ values and higher $a^{*}$ values throughout the storage period $(p<0.05)$. Except on day 0 , acceptability was higher in BWEP than in control and BAA $(p<0.05)$. According to results, WEP can be used as a natural ingredient that improves the shelf life and sensorial qualities of meat products.
\end{abstract}

Keywords: Perilla frutescens var. acuta, beef patty, lipid oxidation, shelf life

Received March 20, 2015; Revised April 29, 2015; Accepted May 11, 2015

\section{Introduction}

Modern dietary patterns have changed to include convenience foods, and consequently, the production and sales volumes of processed meat products in Korea in 2013 increased as much as $54 \%$ and $58 \%$, respectively, compared with those in 2000 (Korea Meat Industries Association, 2014).

Meat undergoes various processes such as grinding, curing, cooking, slicing, and packaging in the production of processed meat products. However, the quality of processed meat product is deteriorated indubitably because they may be exposed to high temperatures and cross-contamination during production, which results in poor shelf life. A major contributor to the deterioration in the quality of processed meat products subjected to heat and storage is lipid oxidation, in which free radicals develop and oxi-

\footnotetext{
*Corresponding author: Samooel Jung, Department of Animal Science and Biotechnology, Chungnam National University, Daejeon 305-764, Korea. Tel: +82-42-821-5774, Fax: +82-42-8259754, E-mail: samooel@cnu.ac.kr
}

dize polyunsaturated fatty acids owing to the decreases in the inherent antioxidant activity in meat (Hygreeva et al., 2014; Jung et al., 2013). Lipid oxidation not only produces rancid odor and flavor but also decreases nutritional value (Frankel, 1996). In addition, meat products are highly susceptible to contamination of spoilage and pathogenic microorganism which results in food-borne illnesses. Therefore, the control of lipid oxidation and microbial contamination in meat products is required. Lipid oxidation and microbial contamination can be generally controlled with synthetic preservatives such as butylated hydroxyl toluene, butylated hydroxyl anisole, sorbic acid, sodium nitrite, and sodium sorbate (Crackel et al., 1988; Hsu and Sun, 2006; Pegg and Shahidi, 2000). However, the use of synthetic preservatives in food is limited by safety concerns and negative view of synthetic food additive (Branen, 1975; Sebranek and Bacus, 2007). Therefore, alternative preservatives in natural ingredients that can control lipid oxidation and microbial contamination in processed meat products have been sought.

Perilla frutescens var. acuta is a naturalized edible plant, and distributed widely throughout the Himalayan 
mountains and East and Southeast Asia. P. frutescens var. acuta is used to treat respiratory disease such as asthma. It is also used as a dye, cosmetic material, and food ingredient (Makino et al., 2003). In addition, P. frutescens var. acuta extract contains various functional compounds with anti-allergenic, anti-inflammatory, antimicrobial, antibacterial, and antioxidant activities (Kim et al., 2004; Kim et al., 2007; Makino et al., 2003; Son et al., 2010). Therefore, this extract may control lipid oxidation and inhibit bacterial proliferation in processed meat products. However, few studies have been conducted to determine the effects of $P$. frutescens var. acuta extract on the quality of these products. Therefore, the objective of this study was to investigate the antioxidant and antibacterial activities of $P$. frutescens var. acuta extract and evaluate the effect of this extract on the shelf life and physicochemical qualities of beef patties during refrigerated storage.

\section{Materials and Methods}

\section{Extraction of Perilla frutescens var. acuta}

Dried mixture of leaves and stems of $P$. frutescens var. acuta was purchased in a local market. Dried mixture (50 g) of leaves and stems of $P$. frutescens var. acuta was added to $1.95 \mathrm{~L}$ of distilled water, then it was extracted for $24 \mathrm{~h}$ in a shaking water bath at $70^{\circ} \mathrm{C}$. Extract was centrifuged at $6,710 \times g$ for $30 \mathrm{~min}(\mathrm{CR} 20 \mathrm{~B} 2$, Hitachi Koki Co., Ltd. Japan) and the supernatant was filtered through Whatman No. 4 filter paper (Whatman Inc., England). The filtrate was lyophilized (Ilshin Co., Korea), and stored until use in a $-70^{\circ} \mathrm{C}$ deep freezer. The extraction was conducted five times.

\section{Antioxidative potential of water extract of Perilla frutescens var. acuta (WEP)}

\section{Total phenolic content}

Total phenolic content was estimated by the Folin-Ciocalteu method (Subramanian et al., 1965). A $0.1 \mathrm{~mL}$ of WEP solution with distilled water was added to the FolinCiocalteu reagent $(0.2 \mathrm{~mL})$, followed by the addition of 3 $\mathrm{mL}$ of sodium carbonate solution $(5 \%)$. The reaction mixture was vortexed and the absorbance was measured with a spectrophotometer (DU 530, Beckman Instruments Inc., USA) at $765 \mathrm{~nm}$ after incubation for $1 \mathrm{~h}$ at $23^{\circ} \mathrm{C}$. The quantification of phenolics was based on the standard curve generated with the use of gallic acid, and expressed as gallic acid equivalent. 1,1-diphenyl-2-picrylhydrazyl (DPPH) radical scavenging activity

DPPH radical scavenging activity of WEP was estimated according to the method of Blois (1958). An $1 \mathrm{~mL}$ of WEP solution with distilled water was added to $1 \mathrm{~mL}$ of methanolic DPPH solution $(0.2 \mathrm{mM})$. The mixture was vortexed and left to stand at room temperature $\left(20-22^{\circ} \mathrm{C}\right)$ for $30 \mathrm{~min}$. A tube containing $1 \mathrm{~mL}$ of distilled water and $1 \mathrm{~mL}$ of methanolic DPPH solution $(0.2 \mathrm{mM})$ served as the control. The absorbance of the solution was measured at $517 \mathrm{~nm}$ using a spectrophotometer (Beckman). The percentage of DPPH radical scavenging was obtained from the following equation: Radical scavenging activity $=[1$ (absorbance of sample / absorbance of control)] $\times 100$. The half maximal effective concentration $\left(\mathrm{EC}_{50}\right)$ of WEP for DPPH radical scavenging was calculated by interpolation from the data and compared with that of L-ascorbic acid as a positive control.

2,2-azinobis-(3 ethylbenzothiazoline-6-sulfonic acid) $\left(\mathrm{ABTS}^{+}\right)$reducing activity

$\mathrm{ABTS}^{+}$reducing activity was determined as the method described by Erel (2004). ABTS was dissolved in distilled water to a $7 \mathrm{mM}$ concentration. The ABTS radical cation was produced by acting the ABTS stock solution with $2.45 \mathrm{mM}$ potassium persulfate (final concentration) in the dark at room temperature for $12-16 \mathrm{~h}$ to allow the completion of radical generation. This solution was then diluted with ethanol so that its absorbance was adjusted to $0.70 \pm 0.02$ at $734 \mathrm{~nm}$. The diluted $\mathrm{ABTS}^{+}$solution $(3 \mathrm{~mL})$ were added to $20 \mu \mathrm{L}$ of WEP solution with distilled water and the absorbance was measured by a spectrophotometer (Beckman) at $734 \mathrm{~nm}$ using ethanol as a blank. The percentage inhibition was calculated by the following equation: $\mathrm{ABTS}^{+}$reducing activity $(\%)=[($ absorbance of control - absorbance of sample) / absorbance of control] $\times$ 100. The half maximal effective concentration $\left(\mathrm{EC}_{50}\right)$ of WEP for $\mathrm{ABTS}^{+}$reducing activity was calculated by interpolation from the data and compared with that of L-ascorbic acid as a positive control.

\section{Antimicrobial potential of WEP}

The antimicrobial potential of $0.3 \%$ and $0.6 \%$ WEP solution with distilled water was measured on Escherichia coli $\mathrm{O} 157: \mathrm{H} 7$. E. coli $\mathrm{O} 157: \mathrm{H} 7$ was obtained from a Korean Collection for Type Culture (KCTC, Korea) and cultivated at $37^{\circ} \mathrm{C}$ for $18 \mathrm{~h}$ in a tryptic soy broth (Difco, Laboratories, USA), and $10 \mathrm{~mL}$ cultures of strain was transferred aseptically to a $50 \mathrm{~mL}$ centrifuge tube and vor- 
texed for $10 \mathrm{~s}$. The tube containing strain was centrifuged $\left(1,950 \times \mathrm{g}\right.$ for $10 \mathrm{~min}$ at $\left.4^{\circ} \mathrm{C}\right)$ in a refrigerated centrifuge (VS-5500, Vision Scientific Co., Korea). The pellet was washed twice with sterile saline $(0.85 \%)$, and suspended in saline to a final concentration of approximately $10^{9} \mathrm{CFU} / \mathrm{mL}$ of the stock inoculum. The $0.1 \mathrm{~mL}$ of WEP solution was mixed with $9.8 \mathrm{~mL}$ of tryptic soy broth and then inoculated with $0.1 \mathrm{~mL}$ of culture suspension of $E$. coli $\mathrm{O} 157: \mathrm{H7}$. The inoculated sample was incubated at $37^{\circ} \mathrm{C}$ for $48 \mathrm{~h}$, and spreaded on tryptic soy agar (TSA, Difco Laboratories, USA). The plates were incubated at $37^{\circ} \mathrm{C}$ for $48 \mathrm{~h}$ and the result was expressed as log of colony forming units ( $\log \mathrm{CFU}) / \mathrm{g}$. Distilled water was used as control ( $0 \% \mathrm{WEP})$.

\section{Preparation of beef patties}

Bottom round of beef was purchased from local market and ground using a meat grinder. Meat batter for manufacture of beef patty was made by mixing ground beef with ingredients (Table 1). Meat batter was divided into 3 treatment groups: (1) control, beef patty without antioxidant; (2) BAA, beef patty with $0.02 \%$ L-ascorbic acid; and (3) BWEP, beef patty with $0.6 \%$ WEP. The meat batter was prepared for 3 times for each treatment. The meat batter put in air-tight container and stored at $4^{\circ} \mathrm{C}$ for $24 \mathrm{~h}$. After storage, $25 \mathrm{~g}$ of meat batter was modeled in a shape with diameter of $5.0 \mathrm{~cm}$ and thickness of $1 \mathrm{~cm}$ using a petri dish and the patties were cooked for $20 \mathrm{~min}$ at $180^{\circ} \mathrm{C}$ until they reached an internal temperature of $75^{\circ} \mathrm{C}$ using an electric steam oven (EON-C305CSM, Tongyang Magic Co., Korea). The patties were vacuum-packaged in a lowdensity polyethylene/nylon vacuum bags $(10 \mathrm{~cm} \times 10 \mathrm{~cm}$; oxygen permeability of $22.5 \mathrm{~mL} / \mathrm{m}^{2} / 24 \mathrm{~h}$ atm at $60 \% \mathrm{RH} /$ $25^{\circ} \mathrm{C}$; water vapor permeability of $4.7 \mathrm{~g} / \mathrm{m}^{2} / 24 \mathrm{~h}$ at $100 \%$ $\mathrm{RH} / 25^{\circ} \mathrm{C}$ ) using a vacuum-packaging machine (FJ-600

Table 1. Formulation of beef patties

\begin{tabular}{cccc}
\hline \hline & \multicolumn{2}{l}{ Treatments } & \\
\hline Ingredients & Control & $\begin{array}{c}\text { L-Ascorbic } \\
\text { acid }\end{array}$ & WEP \\
\hline Ground beef & 75 & 75 & 75 \\
Bread powder & 5 & 5 & 5 \\
Onion & 5 & 5 & 5 \\
Garlic & 2 & 2 & 2 \\
Egg white powder & 2 & 2 & 2 \\
Salt & 1 & 1 & 1 \\
Water & 10 & 10 & 10 \\
Total & 100 & 100 & 100 \\
L-ascorbic acid & & 0.02 & 0.6 \\
WEP & & & \\
\hline
\end{tabular}

${ }^{1}$ Water extract of Perilla frutescens var. acuta
XL; Hankook Fujee Industries Co., Korea) at $650 \mathrm{mmHg}$ after cooling for $30 \mathrm{~min}$ at room temperature and stored for $0,7,14$ and $21 \mathrm{~d}$ at $4^{\circ} \mathrm{C}$.

\section{pH and cooking loss of beef patty}

Beef patty $(5 \mathrm{~g})$ were mixed with $45 \mathrm{~mL}$ of distilled water and homogenized at $1,130 \times \mathrm{g}$, for $1 \mathrm{~min}$ using a homogenizer (T25 basic, IKA GmbH \& Co. KG, Germany). The homogenate was filtered using filter paper (No. 4 filter paper, Whatman) and the filtrate was measured pH using a pH meter (SevenEasy, Mettler-Toledo, Korea). Cooking loss of beef patty was examined by comparing weight of before and after cooking.

\section{Total microbial count analysis}

The total microbial count of beef patty was determined by a slightly modified method of AOAC (2005). Beef patties $(10 \mathrm{~g})$ were blended with sterile saline $(90 \mathrm{~mL})$ for 2 min by using a stomacher (BagMixer ${ }^{\circledR} 400$; Interscience Ind., France). A series of decimal dilutions was prepared using sterile saline. Each diluent $(0.1 \mathrm{~mL})$ was spread in triplicate on tryptic soy agar plates (Difco Laboratories, USA). The plates were incubated at $37^{\circ} \mathrm{C}$ for $48 \mathrm{~h}$, and the microbial counts were expressed as log colony forming units/g ( $\log \mathrm{CFU} / \mathrm{g})$.

\section{Lipid oxidation}

The 2-thiobarbituric acid reactive substances (TBARS) was measured to analyze lipid oxidation of patties as the method described by Jung et al. (2012). Sample (3 g) and $7.2 \%$ butylated hydroxyl toluene $(0.05 \mathrm{~mL})$ were added to $9 \mathrm{~mL}$ of distilled water and the mixture was homogenized at $1,130 \times \mathrm{g}$ for $1 \mathrm{~min}$ using a homogenizer (T25 basic, IKA GmbH \& Co. KG, Germany). The homogenate $(1 \mathrm{~mL})$ was transferred to a test tube, and $2 \mathrm{~mL}$ of TBA- trichloroacetic acid solution (20 mM TBA in $15 \%$ trichloroacetic acid) were added to the test tube. Tubes were heated in a boiling water bath at $90^{\circ} \mathrm{C}$ for $30 \mathrm{~min}$ and cooled in tab water for $10 \mathrm{~min}$. After cooling, the test tube was centrifuged at $2,090 \times \mathrm{g}$ for $20 \mathrm{~min}$. The absorbance of the supernatant was measured at $532 \mathrm{~nm}$ using a spectrophotometer $\left(\mathrm{DU}^{\circledR} 530\right.$, Beckman Instruments Inc., USA). TBARS value was reported as mg malondialdehyde/kg meat.

\section{Instrumental color measurements}

The color (CIE $L^{*}, a^{*}, b^{*}$ ) of each beef patty was measured using a Colorimeter (CM-3500d, Minolta, Japan). Measurements were taken perpendicularly to the surface 
of beef patty with $30 \mathrm{~mm}$ diameter of illumination area at 2 different locations per sample. The result was analyzed using Spectra Magic Software (Minolta, Japan) automatically.

\section{Sensory evaluation}

Sensory evaluation of beef patty was implemented using a group consisting of ten panels who have experience in sensory test of meat and meat product. Patty was reheated at $180^{\circ} \mathrm{C}$ for $3 \mathrm{~min}$ using electric steam oven (EON-C 305CSM, Tongyang Magic Co., Korea) and cut regularly. The scoring of each sample was done on a single sheet using a 9-point hedonic scale $(1=$ extremely dislike, $9=$ extremely like). The sensory parameters scored were color, flavor, taste, texture and acceptability. In addition, ten panels were asked to give a written explanation about sensorial properties of beef patty.

\section{Statistical analysis}

All experiments in this study were performed five individual trials. The general linear model was performed using the raw data, and Tukey's multiple range test was used to compare significant differences between least square mean values $(p<0.05)$. Least square mean values and standard error of the least square means (SEM) are reported. SAS software (version 9.3, SAS Institute Inc., USA) was used for all statistical analyses.

\section{Results and Discussion}

\section{Antioxidative and antimicrobial potential of WEP}

Phenolic compounds are commonly obtained from edible and inedible plants. In this study, the total phenolic content of WEP through five extractions was $80.65 \pm 1.24$ mg gallic acid equivalents/g (Table 2). Previous studies have reported that water and organic solvent extracts of $P$. frutescens var. acuta contain various phenolic compounds such as gallic acid, protocatechuic acid, p-hydroxybenzoic acid, isovanillic acid, chlorogenic acid, caffeic acid, ferulic acid, sinapic acid, and rosmarinic acid (Hong et al., 2011; Jun et al., 2014). The antioxidant activity of phenolic compounds has been shown to occur via free radical quenching (Schlesier et al., 2002).

The half-maximal effective concentrations $\left(\mathrm{EC}_{50}\right)$ of WEP for scavenging DPPH and ABTS radicals were compared with those of L-ascorbic acid. The $\mathrm{EC}_{50}$ values of WEP were $0.437 \mathrm{mg} / \mathrm{mL}$ and $4.509 \mathrm{mg} / \mathrm{mL}$, respectively (Table 2), and those of L-ascorbic acid were 0.038 $\mathrm{mg} / \mathrm{mL}$ and $0.326 \mathrm{mg} / \mathrm{mL}$, respectively. Compared with
Table 2. Total phenolic content (mg GAE $/ \mathrm{g})$ and $\mathrm{EC}_{50}{ }^{2}$ value $(\mathrm{mg} / \mathrm{mL})$ for scavenging of DPPH and ABTS radical of water extract of Perilla frutescens var. acuta (WEP)

\begin{tabular}{cccc}
\hline \hline & Total phenolic & \multicolumn{2}{c}{$\mathrm{EC}_{50}$ value of scavenging } \\
\cline { 3 - 4 } & content & DPPH radical & ABTS radical \\
\hline WEP & $80.65 \pm 1.24^{3}$ & $0.437^{\mathrm{a}}$ & $4.509^{\mathrm{a}}$ \\
L-ascorbic acid & - & $0.038^{\mathrm{b}}$ & $0.326^{\mathrm{b}}$ \\
SEM $^{4}$ & - & 4.1241 & 37.3739 \\
\hline
\end{tabular}

${ }^{1}$ Gallic acid equivalent.

${ }^{2}$ Half maximal effective concentration.

${ }^{3}$ Standard deviation.

${ }^{4}$ Standard errors of the least square means $(n=10)$.

${ }^{a, b}$ Values with different letters within the same column differ significantly $(p<0.05)$.

Table 3. Growth inhibition of water extract of Perilla frutescens var. acuta (WEP) on Escherichia coli 0157:H7

\begin{tabular}{cc}
\hline \hline & Log CFU/g of Escherichia coli $\mathrm{O} 157: \mathrm{H} 7$ \\
\hline Control & $9.10^{\mathrm{a}}$ \\
WEP $0.3 \%$ & $9.14^{\mathrm{a}}$ \\
WEP $0.6 \%$ & $8.21^{\mathrm{b}}$ \\
SEM $^{1}$ & 0.034 \\
\hline
\end{tabular}

${ }^{1}$ Standard errors of the least square means $(n=15)$.

${ }^{\mathrm{a}, \mathrm{b}}$ Values with different letters within the same column differ significantly $(p<0.05)$.

those of WEP, the $\mathrm{EC}_{50}$ values of L-ascorbic acid for DPPH and ABTS radicals were approximately 12 times and 14 times higher, respectively. In this study, the BAA group was used as a positive control. Therefore, we used $0.3 \%$ and $0.6 \%$ WEP as candidate for the BWEP group with the expectation of radical scavenging activity similar to that of L-ascorbic acid and two times higher than that of L-ascorbic acid.

The $0.3 \%$ and $0.6 \%$ WEP solution were used to measure the antimicrobial potential of WEP on E. coli O157: $\mathrm{H} 7$, a pathogenic microorganism. The cell count of $E$. coli O157:H7 in the broth after treatment with distilled water (control), 0.3\% WEP, and 0.6\% WEP were 9.10, 9.14, and 8.21, respectively (Table 3). Significant difference was found only between the control and the $0.6 \%$ WEP treatment groups. Given this result, we added $0.6 \%$ WEP to beef patties for our experiments. The antimicrobial activity of WEP was weak compared to that reported in a previous study in which methanol extract of $P$. frutescens var. acuta inhibited the growth of Salmonella enteritis and Bacillus cereus at concentrations of 4000 and 1000 ppm, respectively (Kim et al., 2004). The antimicrobial activity of plant extracts differs depending on the species and the strain of a pathogen (El-Chaghaby et al., 2014; Jung et al., 2012b). In addition, extraction solvents affect the antimicrobial and antioxidant activities of plant ext- 
Table 4. pH and cooking loss (\%) of beef patty added with water extract of Perilla frutescens var. acuta (WEP)

\begin{tabular}{ccccc}
\hline \hline & \multicolumn{3}{c}{ Treatments } & \multirow{2}{*}{ SEM $^{3}$} \\
\cline { 2 - 4 } & Control & $\mathrm{BAA}^{1}$ & $\mathrm{BWEP}^{2}$ & \\
\hline $\mathrm{pH}$ & $5.86^{\mathrm{X}}$ & $5.67^{\mathrm{Y}}$ & $5.72^{\mathrm{Y}}$ & 0.027 \\
Cooking loss (\%) & $19.95^{\mathrm{Z}}$ & $24.44^{\mathrm{X}}$ & $22.52^{\mathrm{Y}}$ & 0.033 \\
\hline
\end{tabular}

${ }^{1}$ BAA: beef patty added with $0.02 \% \mathrm{~L}-$ ascorbic acid.

${ }^{2}$ BWEP: Beef patty added with $0.6 \%$ water extract of Perilla frutescens var. acuta.

${ }^{3}$ Standard errors of the least square means $(n=15)$.

${ }^{\mathrm{X}-Z}$ Values with different letters within the same row differ significantly $(p<0.05)$

racts. Compared with extracts obtained with water, those obtained with organic solvents have different polarity and contain higher amounts and different types of phenolic compounds (El-Chaghaby et al., 2014). Phenolic compounds are the main components responsible for the antimicrobial activity of plant extracts, and they cause morphological changes in pathogens that increase membrane permeability, cause leakage of vital intercellular constituents, and impair bacterial enzymes (Kim et al., 1995; Wendakoon and Sakaguchi, 1995).

\section{pH and cooking loss}

$\mathrm{pH}$ and cooking loss were measured immediately after the manufacture of the beef patties (Table 4). The $\mathrm{pH}$ in the BAA and BWEP groups were significantly lower than those in the control $(p<0.05)$. The $\mathrm{pH}$ of $P$. frutescens var. acuta extract ranged from 5.4 to 5.6 before lyophilization (data not shown). Therefore, the addition of WEP to beef patty may decrease the $\mathrm{pH}$ in the BWEP group compared with the control. In addition, a previous study found that the $\mathrm{pH}$ of beef patties decreases when ascorbic acid is added (Gioux et al., 2001). Compared with that in the control, cooking loss in the BWEP group was significantly high $(p<0.05)$. This result may be attributable to the lower $\mathrm{pH}$ in the BWEP group. A direct lin- ear relationship between water-holding capacity and $\mathrm{pH}$ in meat has been reported, with cooking loss being negatively related to water-holding capacity (Huff-Lonergan and Lonergan, 2005; Westphalen et al., 2005). However, cooking loss in the BWEP group was significantly lower than that in the BAA group $(p<0.05)$. Although the $\mathrm{pH}$ of the BWEP group was slightly higher than that of the BAA group, the difference was not significant.

\section{Total aerobic bacteria}

The number of total aerobic bacteria in the beef patties was monitored during refrigerated storage at $4^{\circ} \mathrm{C}$ for $21 \mathrm{~d}$ (Table 5). On day 0 , the numbers of total aerobic bacteria in the control, BAA, and BWEP groups were 3.74, 3.33, and $2.85 \mathrm{Log} \mathrm{CFU} / \mathrm{g}$, respectively, with significant differences $(p<0.05)$. Aerobic bacteria proliferated with the increase in storage days in all beef patties. The addition of WEP inhibited the proliferation of aerobic bacteria with significance compared with the control throughout the storage period $(p<0.05)$, with the exception of day 14 . Kim et al. (2011) found that extract of $P$. frutescens var. acuta leaf caused damage in cell membrane of Staphylococcus aureus which led decrease of population of Staphylococcus aureus. Eloff (2001) and Benli et al. (2007) also found the detrimental effect of various plant extract on cell membrane of pathogens. Djeussi et al. (2013) reported that the antibacterial activity of plant extracts was caused by the phenolic compounds and triterpenes contained in plant extracts. The addition of plant extracts containing phenolic compounds retarded increases in aerobic bacteria in pork patties during storage in previous study (Lorenzo et al., 2014). Therefore, the addition of WEP might improve the shelf life of beef patties. However, further studies are needed to elucidate the antimicrobial activity of WEP in beef patties given the inconsistent result on day 14 .

Table 5. Total aerobic bacterial number (Log CFU/g) of beef patty added with water extract of Perilla frutescens var. acuta (WEP) during storage for $21 \mathrm{~d}$ at $4^{\circ} \mathrm{C}$

\begin{tabular}{|c|c|c|c|c|c|}
\hline \multirow{2}{*}{ Treatments } & \multicolumn{4}{|c|}{ Storage days } & \multirow{2}{*}{ SEM } \\
\hline & 0 & 7 & 14 & 21 & \\
\hline Control & $3.74^{\mathrm{aY}}$ & $4.06^{\mathrm{aY}}$ & $5.02^{X}$ & $4.89^{\mathrm{ax}}$ & 0.171 \\
\hline $\mathrm{BAA}^{1}$ & $3.33^{\mathrm{bY}}$ & $3.36^{\mathrm{bY}}$ & $4.89^{\mathrm{X}}$ & $5.31^{\mathrm{aX}}$ & 0.125 \\
\hline $\mathrm{BWEP}^{2}$ & $2.85^{\mathrm{cZ}}$ & $2.95^{\mathrm{bZ}}$ & $4.93^{\mathrm{X}}$ & $4.03^{\mathrm{bY}}$ & 0.087 \\
\hline $\mathrm{SEM}^{3}$ & 0.067 & 0.140 & 0.074 & 0.201 & \\
\hline
\end{tabular}

${ }^{1}$ BAA: beef patty added with $0.02 \%$ L-ascorbic acid.

${ }^{2}$ BWEP: Beef patty added with $0.6 \%$ water extract of Perilla frutescens var acuta.

${ }^{3}$ Standard errors of the least square means $(n=15),{ }^{4}(n=20)$.

${ }^{\mathrm{a}-\mathrm{c}}$ Values with different letters within the same column differ significantly $(p<0.05)$.

${ }^{\mathrm{X}-\mathrm{Z}}$ Values with different letters within the same row differ significantly $(p<0.05)$. 


\section{Lipid oxidation}

The TBARS values of beef patties are shown in Table 6. The initial TBARS values of the control, BAA, and BWEP groups were not significantly different. Compared to those of the control, the TBARS values of the BAA and BWEP groups were significantly lower on days 7 , 14 , and $21(p<0.05)$. The TBARS values of the BAA and BWEP groups did not changed with the increase in storage days, whereas that of the control increased after $7 \mathrm{~d}$ of storage. Phenolic compounds show antioxidative activity by scavenging free radical which is main substance leading lipid oxidation (Schlesier et al., 2002). In the present study, WEP had phenolic compounds and radical scavenging activity. In addition, Hong et al. (2011) found that water extract of of $P$. frutescens var. acuta contained flavonoids, which was strong antioxidant, as well as phenolic compounds. Previous studies have shown that the addition of plant extracts containing phenolic compounds inhibited lipid oxidation in beef patties during storage (Bañón et al., 2007; Jongberg et al., 2011). Base on this result, the addition of WEP could effectively inhibit lipid oxidation in beef patty. No significant difference in TBARS value was found between the BAA and BWEP groups despite the expectation of lower lipid oxidation in the BWEP group was lower than did BAA because $0.6 \%$ WEP might have higher radical scavenging activity than that of $0.02 \%$ ascorbic acid based on these $\mathrm{EC}_{50}$ for $\mathrm{DPPH}$ and ABTS radical. Although reasons were unclear, the inconsistency result between radical scavenging activities of plant extracts and the inhibition effect of lipid oxida-

Table 6. TBARS values (mg malondialdehyde/kg meat) of beef patty added with water extract of Perilla frutescens var. acuta (WEP) during storage for $21 \mathrm{~d}$ at $4^{\circ} \mathrm{C}$

\begin{tabular}{|c|c|c|c|c|c|}
\hline \multirow{2}{*}{ Treatments } & \multicolumn{4}{|c|}{ Storage days } & \multirow{2}{*}{$\mathrm{SEM}^{4}$} \\
\hline & 0 & 7 & 14 & 21 & \\
\hline Control & $1.25^{\mathrm{Y}}$ & $1.51^{\mathrm{aX}}$ & $1.45^{\mathrm{aX}}$ & $1.45^{\mathrm{aX}}$ & 0.041 \\
\hline $\mathrm{BAA}^{1}$ & 1.16 & $1.29^{\mathrm{b}}$ & $1.22^{\mathrm{b}}$ & $1.18^{b}$ & 0.038 \\
\hline $\mathrm{BWEP}^{2}$ & 1.19 & $1.27^{\mathrm{b}}$ & $1.23^{\mathrm{b}}$ & $1.21^{\mathrm{b}}$ & 0.025 \\
\hline $\mathrm{SEM}^{3}$ & 0.045 & 0.042 & 0.024 & 0.023 & \\
\hline
\end{tabular}

${ }^{1}$ BAA: beef patty added with $0.02 \%$ L-ascorbic acid.

${ }^{2}$ BWEP: Beef patty added with $0.6 \%$ water extract of Perilla frutescens var. acuta.

${ }^{3}$ Standard errors of the least square means $(n=15),{ }^{4}(n=20)$.

${ }^{\mathrm{a}, \mathrm{b}}$ Values with different letters within the same column differ significantly $(p<0.05)$.

${ }^{\mathrm{X}, \mathrm{Y}}$ Values with different letters within the same row differ significantly $(p<0.05)$.

Table 7. Instrumental color of beef patty added with water extract of Perilla frutescens var. acuta (WEP) during storage for $21 \mathrm{~d}$ at $4^{\circ} \mathrm{C}$

\begin{tabular}{|c|c|c|c|c|c|}
\hline \multirow{2}{*}{ Treatments } & \multicolumn{4}{|c|}{ Storage days } & \multirow{2}{*}{$\mathrm{SEM}^{4}$} \\
\hline & 0 & 7 & 14 & 21 & \\
\hline \multicolumn{6}{|c|}{$L^{*}$} \\
\hline Control & $52.54^{\mathrm{a}}$ & $52.23^{\mathrm{a}}$ & $51.48^{\mathrm{b}}$ & $52.14^{\mathrm{b}}$ & 0.856 \\
\hline $\mathrm{BAA}^{1}$ & $53.82^{\mathrm{a}}$ & $53.41^{\mathrm{a}}$ & $55.25^{\mathrm{a}}$ & $55.07^{\mathrm{a}}$ & 0.453 \\
\hline $\mathrm{BWEP}^{2}$ & $48.19^{b}$ & $44.90^{\mathrm{b}}$ & $47.71^{\mathrm{c}}$ & $47.21^{\mathrm{c}}$ & 0.748 \\
\hline $\mathrm{SEM}^{3}$ & 0.652 & 0.907 & 0.757 & 0.423 & \\
\hline \multicolumn{6}{|c|}{$a^{*}$} \\
\hline Control & $3.80^{\mathrm{c}}$ & $3.08^{c}$ & $2.72^{b}$ & $2.87^{b}$ & 0.254 \\
\hline BAA & $4.60^{\mathrm{bX}}$ & $4.07^{\mathrm{bXY}}$ & $3.09^{\mathrm{bz}}$ & $3.24^{\mathrm{bYZ}}$ & 0.186 \\
\hline BWEP & $10.79^{\mathrm{aY}}$ & $12.08^{\mathrm{aX}}$ & $9.55^{\mathrm{aZ}}$ & $10.48^{\mathrm{aY}}$ & 0.154 \\
\hline SEM & 0.121 & 0.179 & 0.317 & 0.127 & \\
\hline \multicolumn{6}{|c|}{$b^{*}$} \\
\hline Control & $16.16^{\mathrm{a}}$ & $16.46^{\mathrm{b}}$ & $16.50^{\mathrm{b}}$ & $17.37^{\mathrm{a}}$ & 0.293 \\
\hline BAA & $17.01^{\mathrm{aY}}$ & $17.83^{\mathrm{aX}}$ & $17.61^{\mathrm{aXY}}$ & $17.84^{\mathrm{aX}}$ & 0.178 \\
\hline BWEP & $14.58^{\mathrm{bX}}$ & $14.46^{\mathrm{cX}}$ & $13.26^{\mathrm{cY}}$ & $14.31^{\mathrm{bX}}$ & 0.169 \\
\hline SEM & 0.223 & 0.182 & 0.240 & 0.232 & \\
\hline
\end{tabular}

${ }^{1}$ BAA: beef patty added with $0.02 \%$ L-ascorbic acid.

${ }^{2}$ BWEP: Beef patty added with $0.6 \%$ water extract of Perilla frutescens var. acuta.

${ }^{3}$ Standard errors of the least square means $(n=15),{ }^{4}(n=20)$.

${ }^{a-c}$ Values with different letters within the same column differ significantly $(p<0.05)$.

${ }^{\mathrm{X}-Z}$ Values with different letters within the same row differ significantly $(p<0.05)$. 
tion in pork patty by adding plant extracts was found in the study from Lorenzo et al. (2014).

\section{Instrumental color}

Color is the primary factor used by consumers to judge food acceptability (Serrano et al., 2006). The color of the beef patties in this study is shown in Table 7. BWEP had the lowest $L^{*}$ and $b^{*}$ values among treatments throughout the storage period $(p<0.05)$. Compared with those of the control and BAA groups, the $a^{*}$ values of the BWEP group were significantly higher throughout storage $(p<$ $0.05)$. No significant difference of $L^{*}$ values was found in all treatments with the increase of storage periods. Significant differences in $a^{*}$ and $b^{*}$ values were found in the BAA and BWEP groups during storage periods, but the changes in these values were inconsistent. Color in the BWEP group might have been affected by the color of WEP. Previous study reported that the $L^{*}$ and $b^{*}$ values were lower and the $a^{*}$ values was higher in cooked ground beef with added plant extracts related to the color of the extract throughout the storage periods of $9 \mathrm{~d}$ (Ahn et al., 2007). P. frutescens var. acuta contains anthocyanin, which is a color pigment (Ahn, 2006). In addition,
Ahn et al. (2007) reported that addition of plant extract could improve the red color of cooked ground beef because of their antioxidant activity. The oxidation in cooking process discolors meat products through the formation of hemichrome pigment that occurs when denatured met-myoglobin, which causes brown coloration of meat, and cannot revert to deoxy- and oxy-myoglobin. Therefore, the inhibition of oxidation in BWEP groups might be one of reasons for high $a^{*}$ value in BWEP groups. Although the lipid oxidation results were not consistent with the result of $a^{*}$ value in BAA groups, the $a^{*}$ values in BAA were significantly higher than those of control at days 0 and $3(p<0.05)$.

Consumers generally show a strong preference for red meat products over brown meat products despite knowing that there is no quality difference. Sebranek et al. (2012) reported that consumers prefer a cured color to brown in non-cured meat products. Therefore, because WEP increase the redness of beef patties, it may deserve attention as natural additive for meat products.

\section{Sensory evaluation}

The sensory parameter scores for the beef patties stud-

Table 8. Sensory properties of beef patty added with water extract of Perilla frutescens var. acuta (WEP) during storage for $21 \mathrm{~d}$ at $4^{\circ} \mathrm{C}$

\begin{tabular}{|c|c|c|c|c|c|c|}
\hline \multirow{2}{*}{$\begin{array}{c}\text { Sensory } \\
\text { parameters }\end{array}$} & & \multicolumn{4}{|c|}{ Storage days } & \multirow{2}{*}{ SEM $^{4}$} \\
\hline & & 0 & 7 & 14 & 21 & \\
\hline \multirow{4}{*}{ Color } & Control & $5.13^{b}$ & $5.00^{b}$ & $5.00^{b}$ & $5.00^{b}$ & 0.070 \\
\hline & $\mathrm{BAA}^{1}$ & $5.00^{\mathrm{b}}$ & $5.00^{\mathrm{b}}$ & $5.00^{\mathrm{b}}$ & $4.86^{b}$ & 0.126 \\
\hline & BWEP $^{2}$ & $6.88^{\mathrm{a}}$ & $6.57^{\mathrm{a}}$ & $6.86^{\mathrm{a}}$ & $6.86^{\mathrm{a}}$ & 0.154 \\
\hline & $\mathrm{SEM}^{3}$ & 0.102 & 0.117 & 0.082 & 0.172 & \\
\hline \multirow{4}{*}{ Flavor } & Control & $5.63^{X}$ & $4.86^{\mathrm{aXY}}$ & $5.00^{\mathrm{aXY}}$ & $4.71^{\mathrm{bY}}$ & 0.237 \\
\hline & BAA & $5.00^{\mathrm{X}}$ & $4.29^{\mathrm{bXY}}$ & $3.43^{\mathrm{bYZ}}$ & $3.00^{\mathrm{cZ}}$ & 0.270 \\
\hline & BWEP & 5.38 & $6.29^{\mathrm{a}}$ & $5.29^{\mathrm{a}}$ & $6.43^{\mathrm{a}}$ & 0.336 \\
\hline & SEM & 0.306 & 0.278 & 0.297 & 0.238 & \\
\hline \multirow{4}{*}{ Taste } & Control & $5.88^{X}$ & $5.00^{\mathrm{bXY}}$ & $5.00^{\mathrm{aXY}}$ & $4.71^{\mathrm{bY}}$ & 0.261 \\
\hline & $\mathrm{BA}^{1}$ & $5.00^{\mathrm{X}}$ & $3.86^{\mathrm{cY}}$ & $3.29^{\mathrm{bY}}$ & $2.71^{\mathrm{cY}}$ & 0.295 \\
\hline & BWEP & $5.00^{\mathrm{Y}}$ & $6.57^{\mathrm{aX}}$ & $5.86^{\mathrm{aXY}}$ & $6.86^{\mathrm{aX}}$ & 0.403 \\
\hline & SEM & 0.415 & 0.290 & 0.286 & 0.247 & \\
\hline \multirow{4}{*}{ Texture } & Control & $6.00^{\mathrm{aX}}$ & $4.86^{\mathrm{bY}}$ & $5.00^{\mathrm{bY}}$ & $5.00^{\mathrm{bY}}$ & 0.195 \\
\hline & BAA & $5.00^{\mathrm{bX}}$ & $3.71^{\mathrm{cY}}$ & $3.71^{\mathrm{cY}}$ & $3.57^{\mathrm{cY}}$ & 0.321 \\
\hline & BWEP & $6.25^{\mathrm{a}}$ & $6.29^{\mathrm{a}}$ & $6.00^{\mathrm{a}}$ & $6.29^{\mathrm{a}}$ & 0.239 \\
\hline & SEM & 0.211 & 0.247 & 0.208 & 0.347 & \\
\hline \multirow{4}{*}{ Acceptability } & Control & $6.13^{\mathrm{aX}}$ & $5.00^{\mathrm{bY}}$ & $5.00^{\mathrm{bY}}$ & $4.71^{\mathrm{bY}}$ & 0.214 \\
\hline & BAA & $5.00^{\mathrm{bX}}$ & $3.86^{\mathrm{cY}}$ & $3.57^{\mathrm{cYZ}}$ & $2.71^{\mathrm{cZ}}$ & 0.258 \\
\hline & BWEP & $5.50^{\mathrm{abY}}$ & $6.43^{\mathrm{aXY}}$ & $6.14^{\mathrm{aXY}}$ & $6.86^{\mathrm{aX}}$ & 0.273 \\
\hline & SEM & 0.254 & 0.261 & 0.228 & 0.247 & \\
\hline
\end{tabular}

${ }^{1}$ BAA: beef patty added with $0.02 \%$ L-ascorbic acid.

${ }^{2}$ BWEP: Beef patty added with $0.6 \%$ water extract of Perilla frutescens var acuta.

${ }^{3}$ Standard errors of the least square means $(n=30),{ }^{4}(n=40)$.

${ }^{\text {a-c }}$ Values with different letters within the same column differ significantly $(p<0.05)$.

${ }^{\mathrm{X}-Z}$ Values with different letters within the same row differ significantly $(p<0.05)$. 
ied are shown in Table 8. As expected, the color score in the BWEP group was significantly higher than those in the control and BAA groups throughout the storage pe$\operatorname{riod}(p<0.05)$. On day 0 , the flavor score of the beef patties was not significantly different among treatments. However, compared with the BAA group, the BWEP group had a significantly higher flavor score on days 7 and 14 , and the BWEP flavor score was significantly higher than those of the control and BAA groups on day $21(p<0.05)$. Taste scores were also not significantly different among treatments on day 0 . On days 7 and 21, the taste score for the BWEP group was significantly higher than those of the control and BAA groups $(p<0.05)$. The texture scores of the BWEP and control groups were similar. During storage, the texture score of the BWEP group was significantly higher than those of the control and BAA groups on days 7, 14, and $21(p<0.05)$. Compared with that of the control and BAA groups, the acceptability of the BWEP group was significantly higher throughout the storage period, except on day $0(p<0.05)$.

In their written evaluations of the sensory properties of the beef patties, panel members responded that they perceived WEP flavor in the BWEP group only in day 0 of storage, whereas they perceived an undesirable flavor and acidic taste in the control and BAA groups as the number of storage days increased. They perceived no undesirable flavors or acidic taste in the BWEP group throughout the storage period. Georgantelis et al. (2007) reported that rancid flavor is detectable in meat products when the TBARS value is higher than $0.6 \mathrm{mg}$ malondialdehyde $/ \mathrm{kg}$. In this study, the TBARS values of the beef patties were above $0.6 \mathrm{mg}$ malondialdehyde/kg immediately after manufacture in all treatment groups. Therefore, a rancid flavor in the patties could have been detected by members of the sensory panels. However, the rancid flavor in the BWEP group was apparently covered by WEP. Jung and Lee (2000) reported that $P$. frutescens var. acuta has masking effects on undesirable flavors in meat and fish because it generates various volatile flavor compounds.

\section{Conclusion}

The WEP produced in this study contained levels of phenolic compounds as high as $80.65 \pm 1.24 \mathrm{mg}$ gallic acid equivalents/g and showed antioxidative potential on DPPH and ABTS radicals and antimicrobial potential on E. coli O157:H7. The addition of WEP to beef patties inhibited lipid oxidation and the growth of aerobic bacteria in beef patties during storage for $21 \mathrm{~d}$ at $4^{\circ} \mathrm{C}$. In addition, redness and sensory parameter scores increased in beef patties to which WEP was added. Therefore, we concluded that WEP can be used as a natural additive to improve the shelf life and sensory qualities of meat products.

\section{Acknowledgements}

This study was financially supported by research fund of Chungnam National University.

\section{References}

1. Ahn, H. (2006) Available components of Chajogi at different harvest periods. Korean J. Food Preserv. 13, 703-707.

2. Ahn, J., Grun, I. U., and Mustapha, A. (2007) Effects of plant extracts on microbial growth, color change, and lipid oxidation in cooked beef. Food Microbiol. 24, 432-432.

3. AOAC (2005) Official methods of analysis ( $18^{\text {th }}$ revised ed.), Washington, DC: Association of Official Analytical Chemists.

4. Benli, M., Kaya, I., and Yigit, N. (2007) Screening antimicrobial activity of various extracts of Artemisia dracunculus L. Cell Biochem. Fun. 25, 681-686.

5. Blois, M. S. (1958). Antioxidant determination by the use of a stable free radical. Nature 181, 1199-1200.

6. Branen, A. L. (1975) Toxicology and biochemistry of butylated hydroxyanisole and butylated hydroxytoluene. $\mathrm{J}$. Am. Oil Chem. Soc. 52, 59-63.

7. Crackel, R. L., Gray, J. I., Booren, A. M., Pearson, A. M., and Buckley, D. J. (1988) Effect of antioxidants on lipid stability in restructured beef steaks. J. Food Sci. 53, 656-657.

8. Djeussi, D. E., Noumedem J. A. K., Seukep, J. A., Fankam, A. G., Voukeng, L. K., Tankeo, S. B., Nkuete A. H. L., and Kuete, V. (2013) Antibacterial activities of selected edible plants extracts against multidrug-resistant Gram-negative bacteria. BMC Complement. Altern. Med. 13, 164-171.

9. El-Chaghaby, G. A., Ahmad, A. F., and Ramis, E. S. (2014) Evaluation of the antioxidant and antibacterial properties of various solvents extracts of Annona squamosa L. leaves. Arab. J. Chem. 7, 227-233.

10. Eloff, J. N. (2001) Antibacterial activity of Marula (Sclerocarya birrea (A. rich.) Hochst. subsp. caffra (Sond.) Kokwaro) (Anacardiaceae) bark and leaves. J. Ethnopharmacol. 76, 305-308.

11. Erel, O. (2004). A novel automated direct measurement method for total antioxidant capacity using a new generation, more stable ABTS radical cation. Clinical Biochem. 37, 277285.

12. Frankel, E. N. (1996) Antioxidants in lipid foods and their impact on food quality. Food Chem. 57, 51-55.

13. Georgantelis, D., Blekas, G., Katikou, P., Ambrosiadis, I., and Fletouris, D. J. (2007) Effect of rosemary extract, chitosan and alpha-tocopherol on lipid oxidation and colour stability during frozen storage of beef burgers. Meat Sci. 75, 256-264. 
14. Hong, E., Park, K. H., and Kim, G. H. (2011) Phenolicenriched fractions from Perilla frutescens var. acuta: Determinating rosmarinic acid and antioxidant activity. J. Food Biochem. 35, 1637-1645.

15. Hsu, S. Y. and Sun L. Y. (2006) Effects of salt, phosphates, potassium sorbate and sodium erythorbate on qualities of emulsified meatball. J. Food Eng. 73, 246-252.

16. Huff-Lonergan, E. and Lonergan, S. M. (2005) Mechanisms of water-holding capacity of meat: The role of postmortem biochemical and structural changes. Meat Sci. 71, 194-204.

17. Hygreeva, D., Pandey, M. C., and Radhakrishna, K. (2014) Potential applications of plant based derivatives as fat replacers, antioxidants and antimicrobials in fresh and processed meat products. Meat Sci. 98, 47-57.

18. Jongberg, S., Skov, S. H., Torngren, M. A., Skibsted, L. H., and Lund, M. N. (2011) Effect of white grape extract and modified atmosphere packaging on lipid and protein oxidation in chill stored beef patties. Food Chem. 128, 276-283.

19. Jung, M. S. and Lee, M. S. (2000) Analysis of volatile flavor components from Perilla frutescens var. acuta and sensory evaluation as natural spice. Korean J. Soc. Food Sci. Technol. 16, 221-225.

20. Jung, S., Jo, C., Kang, M., Ahn, D. U., and Nam, K. C. (2012a) Elucidation of antioxidant activity of phosvitin extracted from egg yolk using ground meat. Korean J. Food Sci. An. 32, 162-167.

21. Jung, S., Nam, K. C., Ahn, D. U., Kim, H. J., and Jo, C. (2013) Effect of phosvitin on lipid and protein oxidation in ground beef treated with high hydrostatic pressure. Meat Sci. 95, 8-13.

22. Jung, S., Yun, H., Kim, H. J., Ham, J. S., Kim, I. S., Lee, M., and Jo, C. (2012b) Inactivation efficiency of Escherichia coli and Listeria monocytogenes in groun pork by combination of natural food ingredients and high pressure processing. Korean J. Food Sci. An. 32, 1-5.

23. Kim, D. H., Kim, Y. C., and Choi, U. K. (2011) Optimization of antibacterial activity of Perilla frutescens var. acuta leaf against Staphylococcus aureus using evolutionary operation factorial design technique. Int. J. Mol. Sci. 12, 2395-2407.

24. Kim, J. M., Marshall, M. R., Cornell, J. A., Preston, J. F., and Wei, C. I. (1995) Antibacterial activity of carvacrol, citral, and geraniol against Salmonella typhimurium in culture medium and on fish cubes. J. Food Sci. 60, 1364-1368.

25. Kim, M. H., Kang, W. W., Lee, N. H., Kwoen, D. J., and Choi, U. K. (2007) Antioxidant of extract with water and ethanol of Perilla frutescens var. acuta Kudo leaf. J. Korean
Soc. Appl. Biol. Chem. 50, 327-333.

26. Kim, S. A., Seo, J. E., and Bae, J. H. (2004) Effect of Perilla frutescens extract on the growth of food borne pathogens. $J$. East Asian Soc. Dietary Life 14, 472-478.

27. Korea Meat Industries Association 2014 Statistics of current meat import status. http://www.kmia.or.kr/infocenter/infocenter2.html. Accessed on January 19, 2015.

28. Lorenzo, J. M., Sineiro, J., Amado, I. R., and Franco, D. (2014) Influence of natural extracts on the shelf life of modified atmosphere-packaged pork patties. Meat Sci. 96, 526534.

29. Makino, T., Furata, Y., Wakushima, H., Fujii, H., Saito, K., and Kano, Y. (2003) Anti-allergic effect of Perilla frutescens and its active constituents. Phytother. Res. 17, 240-243.

30. Pegg, R. B. and Shahidi, F. (2000). Nitrite curing of meat: The N-nitrosamine problem and nitrite alternatives. Trumbull, CT: Food \& Nutrition Press, Inc.

31. Schlesier, K., Harwat, M., Bohm, V., and Bitsch, R. (2002) Assessment of antioxidant activity by using different in vitro methods. Free Radical Res. 36, 177-187.

32. Sebranek, J. G. and Bacus, J. (2007) Natural and organic cured meat products: Regulatory, manufacturing, marketing, quality, and safety issues. American Meat Science Association white paper series, no. 1.

33. Sebranek, J. G., Jackson-Davis, A. L., Myers, K. L., and Lavieri, N. A. (2012) Beyond celery and starter culture: Advances in natural/organic curing processes in the United States. Meat Sci. 92, 267-273.

34. Serrano, A., Cofrades, S., and Jimenez-Colmenero, F. (2006) Characteristics of restructured beef steak with different proportions of walnut during frozen storage. Meat Sci. 72, 108115.

35. Son, H. U., Heo, J.C., Seo, S. M., and Lee, S. H. (2010) Effects of Perilla frutescens L. on anti-oxidant and antiinflammation activity. Korean J. Food Preserv. 17, 757-761.

36. Subramanian, K. N., Padmanaban, G., and Sarma, P. S. (1965) Folin-Ciocalteu reagent for the estimation of siderochromes. Anal. Biochem. 12,106-112.

37. Wendakoon, C. N. and Sakaguchi, M. (1995) Inhibition of amino-acid decarboxylase activity of enterobacter-aerogenes by active components in spices. J. Food Prot. 58, 280-283.

38. Westphalen, A. D., Briggs, J. L., and Lonergan, S. M. (2005) Influence of $\mathrm{pH}$ on rheological properties of porcine myofibrillar protein during heat induced gelation. Meat Sci. 70, 293-299. 